\title{
MIDAS
}

Museus e estudos interdisciplinares

$8 \mid 2017$

Dossier temático "Objetos e museus: biografias, narrativas e vínculos identitários"

\section{Patrimonios, objetos e historias de vida. Análisis de propuestas educativas desde el Observatorio de Educación Patrimonial en España}

Objects and life stories. Analysis of educational proposals from The Spanish Heritage Education Observatory

Olaia Fontal Merillas, Silvia García-Ceballos, Borja Aso Morán y Marta Martínez Rodríguez

\section{(2) OpenEdition}

Journals

Edición electrónica

URL: http://journals.openedition.org/midas/1310

DOI: $10.4000 /$ midas. 1310

ISSN: 2182-9543

Editor:

Alice Semedo, Paulo Simões Rodrigues, Pedro Casaleiro, Raquel Henriques da Silva, Ana Carvalho

Referencia electrónica

Olaia Fontal Merillas, Silvia García-Ceballos, Borja Aso Morán y Marta Martínez Rodríguez, « Patrimonios, objetos e historias de vida. Análisis de propuestas educativas desde el Observatorio de Educación Patrimonial en España », MIDAS [En línea], 8 | 2017, Puesto en línea el 31 julio 2017, consultado el 19 abril 2019. URL : http://journals.openedition.org/midas/1310 ; DOI : 10.4000/ midas. 1310

Este documento fue generado automáticamente el 19 abril 2019.

Midas is licensed under a Creative Commons Attribution-NonCommercial-ShareAlike 3.0 International License 


\section{Patrimonios, objetos e historias de vida. Análisis de propuestas educativas desde el Observatorio de Educación Patrimonial en España}

Objects and life stories. Analysis of educational proposals from The Spanish Heritage Education Observatory

Olaia Fontal Merillas, Silvia García-Ceballos, Borja Aso Morán y Marta Martínez Rodríguez

\section{NOTA DEL EDITOR}

Artigo recebido a 31.03.2017

Aprovado para publicação a 28.06.2017

\section{Introducción}

1 Entendemos el patrimonio como una de las mayores riquezas que poseemos. Material o inmaterial y de naturaleza diversa es, en ocasiones, huella de nuestra memoria, rastro de nuestra historia o vínculo con los antepasados (Criado 2001). Recordar en este sentido los conocidos como retratos de Fayum - reciben este nombre por su localización geográfica -. En origen, en tiempos del Imperio romano en el Bajo Egipto, eran retratos naturalistas de personas difuntas pintados sobre tabla - o sobre lino, los menos -, los cuales poseían una doble función pictórica: retratos de identidad que, valga la redundancia, identificaban al difunto ante Anubis en su viaje al Más Allá; y servían como recuerdo del fallecido para su familia doliente (Berger 2002). De lo anterior destaca una palabra en cualquiera de sus categorías gramaticales: recuerdo, recordar, etc. Y es que el patrimonio es un recuerdo, un elemento con un cargado componente emocional que nos vincula con el pasado y nos 
proyecta al futuro (Capel 2014). Sin olvidar que en el tiempo presente sirve como manifestación cultural e identitaria de un colectivo o pueblo.

Para que estos vínculos se hagan efectivos, entra en juego el papel mediador de la educación patrimonial. Desvallées y Mairesse (2010) aluden a la educación como una dimensión activa de acompañamiento en los procesos de transmisión, que está ligada a la noción de despertar, lo que se refiere a suscitar la curiosidad, y conducir a la reflexión. Además, señalan que la educación procura desarrollar los sentidos y la toma de conciencia. La puesta en funcionamiento de la mente y de las emociones que entran en juego, a las que Mora (2013) alude como ventanas del conocimiento. A través de las estrategias didácticas, cobra sentido, la experiencia patrimonial y, por tanto, se consigue que nuestra mirada o nuestros conocimientos previos muden su significado. En base a esta idea, existe una perseverancia en la reconceptualización del patrimonio, como las relaciones que las personas establecen con los bienes desde una perspectiva identitaria y simbólico-social (Fontal 2013).

Uno de los modelos referentes entre los enfoques más contemporáneos de la educación patrimonial, es el promulgado por Juanola y Calbó $(2007,38)$, quienes inciden en la implicación de la «educación sensorial, perceptiva, corporal, espacial, emocional, expresiva y comunicativa, activa, comprensiva, estética, cognitiva, crítica, ambiental, multicultural, ética e inclusiva». Aspectos que se han visto presentes en las prácticas educativas que aquí se recogen.

\section{Marco conceptual}

4 La educación patrimonial se ocupa, desde una visión holística y humanista, de sensibilizar a las personas con nuestros bienes y herencias (Fontal 2003), por ello es nuestro instrumento de mediación para lograr la valoración y socialización del patrimonio.

5 La necesidad de explorar nuevos territorios en el campo de la educación patrimonial nos lleva a tornar la mirada hacia horizontes internacionales, tratando de triangular experiencias que sean aporte efectivo para la materia y sistema de mejora en la práctica educativa. En este caso, se presentan algunas acciones educativas sobresalientes localizadas en los contextos español, portugués y brasileño, fruto de estancias de pesquisa desarrolladas por los investigadores, que han facilitado el conocimiento y la aproximación a las propuestas desarrolladas en los ámbitos formal no formal e informal de dichos territorios.

6 Tratando de abocetar una cartografía de experiencias, en este artículo se recogen acciones educativas singulares que, a modo de esqueleto, van arrojando claves de trabajo y dando forma a una disciplina ya consolidada como es la educación patrimonial (Martín 2012; Fontal y Juanola 2015; Fontal y Ibáñez 2017). Así mismo, se aportan reflexiones fruto de un proceso de formación e investigación en desarrollo, que surge tras la revisión teórica sobre la materia (Fontal y Ibáñez 2017) y la aproximación al campo de estudio desde un enfoque cualitativo.

\section{Marco del estudio}

7 Este estudio se enmarca en el Observatorio de Educación Patrimonial (OEPE), una sucesión de tres proyectos de I+D+i a través de los cuales se configura y gestiona una base 
de datos donde se inventarían y evalúan programas de educación patrimonial localizados dentro del ámbito nacional e internacional (Fontal 2016). Esta base de datos sólo es accesible para el equipo investigador y en ella se desarrollan las labores de localización, inventario y evaluación de proyectos de educación patrimonial. La propia base nos sirve de universo muestral, donde a través del motor de búsqueda incorporado, se realizan búsquedas en torno a descriptores definidos por el investigador. En este caso, los programas se localizaron a través de la base atendiendo a los descriptores identidad y vínculo por estar estrechamente ligado con la temática del monográfico; y también a través del intercambio científico desarrollado durante los años 2015-2016, donde se han ido encontrando experiencias reseñables.

El OEPE posee un modelo propio de análisis (Fontal y Redondo 2016), consistente en siete fases de trabajo consecutivas y discriminatorias entre sí. La primera parte del modelo (fases 1, 2, 3 y 4) responde a la localización, discriminación, inventario y análisis estadístico descriptivo de los programas que se incluyen dentro de la base. Una segunda parte cuantitativa de carácter exploratorio (fases 5 y 6), desarrollada a través de un sistema de evaluación basado en estándares (Stake 2006), donde los programas son evaluados a través de ítems basados en la calidad del diseño educativo. Y una última fase cualitativa (fase 7) que responde a un estudio explicativo - estudio de caso - de los programas más significativos (Stake 2005; Martínez Carazo 2006; Fontes et al. 2010). El método se basa en un enfoque mixto de investigación que posee una parte de triangulación concurrente donde están implicadas las sete fases del estudio para contrastar y combinar los resultados obtenidos de las mismas.

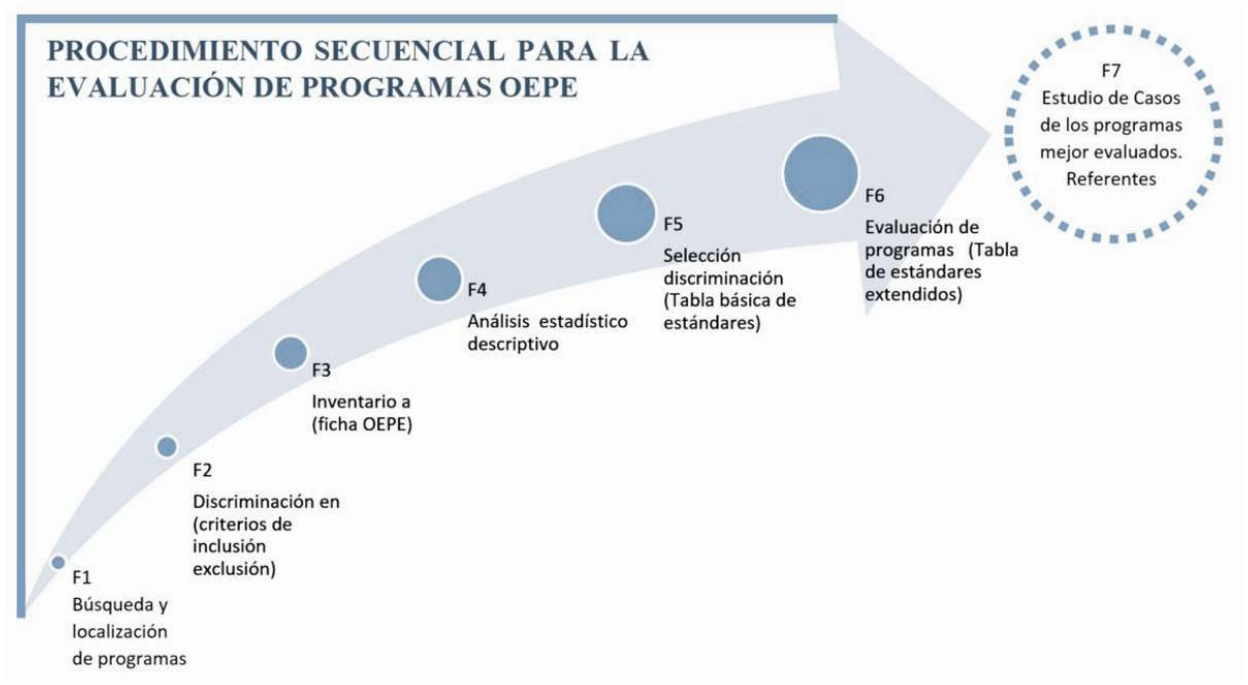

Fig. 1 - Procedimiento secuencial para la evaluación de programas OEPE

Para este estudio, por la perspectiva interaccionista y el paradigma naturalista aplicado (Popkewitz 1988), solo exponemos esta última fase metodológica que posee un carácter más pormenorizado permitiendo una aproximación más humanista a la materia, basado en estudios de caso y análisis de contenido (Piñuel Raigada 2002). 


\section{Referente epistemológico}

10 El estudio que se presenta se define desde la corriente del interaccionismo simbólico, en tanto se centra en los participantes, en la sociedad, en las personas. Blumer (1969), precursor del interaccionismo, enuncia que las personas actúan sobre los objetos de su mundo e interactúan con otras personas partiendo de los significados que los objetos y las personas tienen para ellas, lo que denominamos como el establecimiento de vínculos. Este proceso es el que se define como patrimonialización (Gómez-Redondo 2014); emerge a partir de las relaciones que germinan entre las personas y los objetos, además, señala que los significados son fruto de la interacción social y la comunicación esencial para el ser humano, junto a la confección del individuo y su conducta -socialización del patrimonio -. El interaccionismo simbólico se sitúa dentro del paradigma interpretativo de origen cualitativo y humanista, que no pretende predecir y explicar sino comprender y describir lo particular frente a lo general, apoyándose en una descripción ideográfica y en profundidad, de manera que el objeto estudiado queda claramente individualizado.

11 Mediante esta metodología, hemos podido trabajar de una manera muy próxima y personal a través de entrevistas a los agentes implicados, el análisis de contenido sobre la planificación de las acciones o propuestas educativas y, por último, con el desarrollo de estudios de caso que dotan la muestra escogida de un carácter analítico más profundo y detallado de su diseño e implementación, a través de la aproximación al campo observacional focalizando nuestra atención en la práctica (Simons 2011).

\section{Objeto y objetivos}

12 El objeto de este estudio es el análisis de prácticas educativas o artísticas en torno al patrimonio, donde las narrativas o historias de vida de las personas tengan un papel principal relacionado con la práctica, es decir, hablamos de que o bien en el proceso creador, o bien en la arquitectura educativa de la propuesta, estén presentes algunas partes de la secuencia de patrimonialización diseñada por Fontal (2003), que incidan en la sensibilización o la identización del patrimonio. Partiendo de esta idea, se establecieron los siguientes objetivos específicos:

OE1: Identificar ejemplos de buenas prácticas educativas en torno al patrimonio a través de la evaluación mediante el método OEPE.

OE2: Triangular experiencias destacadas entre España, Portugal y Brasil.

OE3: Puesta en valor de las historias de vida en los procesos educativos y creativos.

OE4: Profundizar en los enfoques, modelos didácticos y grado de adecuación de las propuestas existentes en base a una serie de estándares de calidad y el aporte de prácticas referentes al campo de estudio.

OE5: Obtener resultados que permitan reflexionar y replantear la educación patrimonial con fines identitarios.

\section{Población y muestra}

Como se ha especificado anteriormente, la localización de los programas se desarrolló a través de la base de datos con los descriptores identidad y vínculo - muestreo -. En este 
proceso se localizaron $(\mathrm{N}=238)$ programas educativos que giran en torno a la preservación, valorización y visibilización del patrimonio personal - material o inmaterial - desde una perspectiva identitaria y vinculante (Martínez Rodríguez y Fontal 2016). Estos programas - el objeto de estudio de la investigación - conforman la muestra de análisis de la que se extraen las propuestas. Tras un análisis de contenido sobre las hojas de inventario, se han ido seleccionando los programas aquí reseñados.

\section{El patrimonio, huella de la memoria y crisol de la cultura}

El patrimonio que poseemos es rico en matices que dependen del entorno y se tamizan a través de las personas que lo experimentan, de las que lo disfrutan o de las que lo consideran parte importante de su vida. Somos dueños de un contexto, de unas posesiones comunes o personales $\mathrm{y}$, como tal, en nuestra función de guardianes de la memoria, resulta imprescindible velar por su permanencia, debiendo sustentar en la sociedad las bases del respeto, cuidado, trasmisión y difusión; para lo que nuestro instrumento más potente es la educación y la sensibilización con, por y para el patrimonio (Cantón 2009).

Este patrimonio del que hablamos es aquel que nos circunda como individuos, ya sea un recuerdo, una canción, una danza, una lengua, un proverbio, una imagen, un lugar, una persona o un objeto; todo cuanto nos rodea es susceptible de ser patrimonio, o en su actual efecto, patrimoniable, ya que «es absolutamente fundamental como uno de los niveles en los que se constituyen las identificaciones y las formas de identidad» (Mouffe 2007, 26). Fracasso (2016) define lo patrimoniable como el valor patrimonial que queda por fuera de lo hegemónicamente reconocido y que pertenece realmente a lo popular, un aspecto presente en las propuestas que aquí se recogen. El valor de las cosas fluctúa en función de su historia de vida, de su memoria histórica, de la importancia dispuesta por las personas o grupos que lo poseen; del valor que se le otorga, no del que usufructúa como objeto en sí mismo, sino del que es dotado por cada una de las culturas, los pueblos o sujetos. En su discurso, Fracasso añade sobre el concepto de lo patrimoniable, la idea de utopía concreta por Ernst Bloch (Martínez Contreras 2004), que se traduce en los conceptos todavía no (carencia) y aún - no (esperanza), lo que tomamos en este caso como un punto de inicio para la puesta en valor del patrimonio personal.

Denominamos patrimonio personal al propio del individuo que no tiene por qué poseer significaciones colectivas, normalmente está formado por nuestras raíces, por las pertenencias heredadas de los individuos más próximos o filiales $o$, tal vez, surgidas de la propia vivencia dotada de valor y sentido para la persona. No es un patrimonio para todos, sino un patrimonio individual y propio que conforma partes de sí mismo. No hablamos solo de los bienes que heredamos sino de las circunstancias, la historia personal y la historia social que es dotada de un valor individualizado normalmente de carácter emocional o afectivo. Este valor desplaza al valor material o económico del propio bien.

17 Así como entendemos la riqueza del patrimonio por su valor para las personas, desde nuestra línea de investigación apoyamos la necesidad de su conocimiento e intercambio y, por ende, debemos resaltar su visibilización, su cometido en la activación de concienciar a las personas sobre la conservación y preservación de su patrimonio y su oralidad; la transmisión de las tradiciones, las actitudes de rescate de la memoria, la cohesión entre 
las culturas y el enriquecimiento entre contextos que convergen en el sentido de sus objetivos patrimoniales. En este sentido no hablamos solo de los elementos patrimoniales materiales sino de la propiedad inmaterial.

Según la Convención para la Salvaguardia del Patrimonio Cultural Inmaterial de la UNESCO (2003, artículo 2), el patrimonio cultural inmaterial (PCI) «es el crisol de nuestra diversidad cultural y su conservación, una garantía de creatividad permanente». Esta define el PCI más concretamente como los usos, representaciones, expresiones, conocimientos y técnicas que las comunidades, los grupos y, en algunos casos, los individuos reconozcan como parte integrante de su patrimonio cultural. En lo que respecta a esta categoría de patrimonio, UNESCO enuncia: se transmite de generación en generación, es recreado constantemente por las comunidades y grupos en función de su entorno, su interacción con la naturaleza y su historia; infunde a las comunidades y los grupos un sentimiento de identidad y de continuidad; promueve el respeto de la diversidad cultural y la creatividad humana; es compatible con los instrumentos internacionales de derechos humanos existentes y cumple los imperativos de respeto mutuo entre comunidades, grupos e individuos y de desarrollo sostenible. Por tanto, encontramos en esta parcela del patrimonio una herramienta clave para los objetivos definidos en nuestra práctica como la sensibilización, la valorización y la socialización del patrimonio (Fontal 2013), para incentivar la salvaguarda del mismo.

\section{Muestreo de prácticas referentes sobre el patrimonio: relatos y vínculos de identidad}

Las experiencias y su contexto sociocultural nos definen, nos moldean como persona. Los objetos que poseemos, la herencia material e inmaterial, reflejan nuestro yo, nuestras raíces o nuestro crecimiento. Las cicatrices visibles o invisibles de la piel y las marcas que dejamos en el mundo sobre nuestra existencia cuentan nuestra historia y dan fe de nuestro paso. Si la suma de estas expresiones nos conforma como persona, el patrimonio de la vida es conformador de nuestra identidad y constructo como individuo. GómezRedondo (2012) define a este proceso de identidad como una miscelánea relacional, un microcosmos multisustancial de ideas, afectos, actitudes, creencias, valores, categorías, recuerdos, objetos, etc. Este microcosmos en constante movimiento y transformación por el estado cambiante de la vida y los elementos que nos rodean, convierte este proceso de identidad en una constante, por lo que nos habla de proceso de identización, la potencia frente al hecho. Este proceso es complejo y creativo en tanto que es una redefinición constante del ser humano.

Precisamente en función del uso que le otorgue la sociedad, el patrimonio puede ser un instrumento de identificación colectiva. (Ballart y Juan-Tresserras 2007; cit. por MEC y Gobierno de Córdoba 2010, 5)

La psicología define la identidad como una necesidad básica del ser humano. A lo largo de la vida todos los seres nos planteamos preguntas vitales, quién soy o cómo soy, sin embargo, esta respuesta no es absoluta, se encuentra en un estado cambiante y dependiente del contexto o la circunstancia. Por tanto, podemos afirmar que la identidad tiene que ver con nuestra historia de vida, la cual será influida por el momento y lugar en que vivimos, esta idea está respaldada por Fontal (2003) desde su línea de investigación, entonces emergente, sobre la educación patrimonial: 
Los individuos son "portadores" de determinados valores culturales $\mathrm{y}$, como tales, los sienten, los utilizan para diferenciarse de otros sujetos y de otras culturas y, en definitiva, se consideran pertenecientes a esa o esas culturas, lo que a su vez les permite estar contextualizados. De manera que, como sujetos de estos valores, los individuos efectúan diferentes usos de ellos, que van desde la configuración de su carácter, hasta la identificación como parte de un contexto, pasando por la asunción de diferentes roles culturales. (Fontal 2003, 54)

21 La sociedad es cada vez más consciente de la ineludible necesidad de plantear el valor social y el uso del patrimonio en todas sus manifestaciones, su apropiación (Cerillos 1998). Prueba de ello es el incesante crecimiento de las acciones de puesta en valor del patrimonio personal, la preservación y la revitalización de la memoria. Todas estas reflexiones han sido construidas a partir del análisis de las prácticas recogidas en este estudio. Tras las fases de análisis, destacamos algunos programas que han obtenido un alto grado de calidad en su diseño educativo a través de las fases del método OEPE. En este caso, se presentan una serie de experiencias desde un análisis descriptivo del fenómeno observado (Fontes de Gracia et al. 2010), tratando de destacar de cada una de ellas los aspectos más significativos de su concepción, diseño o implementación.

\section{Las personas, agentes para la preservación de la memoria: "Tesoros vivos de la cultura"}

Encontramos el proyecto portugués "Educação e Património Cultural: Escolas, Objetos e Práticas" donde se propuso un trabajo desde la perspectiva investigativa sobre el patrimonio cultural de la educación, tratando de redescubrir la historia de la escuela. El proyecto señala la necesidad de preservar los materiales documentales y subraya la importante dimensión de la divulgación social del patrimonio, mediante la configuración de un museo virtual creado a través de las aportaciones de la ciudadanía (narrativas sobre la arquitectura escolar, su equipamiento, materiales didácticos, medios audiovisuales o cuadernos escolares, entre otros) y la construcción de identidades por la conexiones establecidas en los recorridos de vida que marcaron a las personas que frecuentaron la escuela.

La revitalización de la memoria se encuentra en propuestas tales como el proyecto "Ventanas a Tetuán" (Calvo 2015), "Memorias de Madrid: una Ciudad Construía de Recuerdos" (Sánchez 2015), "Memoria de los Barrios” (Pedreira et al. 2015); o el proyecto desarrollado a través de la Villa de Paranapiacaba "Plataforma Paranapiacaba. Memoria y Experimentación", una villa de construcción colonial, cuya acción educativa para la conservación y difusión de la misma, basa sus líneas de actuación en la historia oral y la memoria individual y colectiva de sus habitantes, un proyecto colaborativo que elabora una cartografía socioafectiva como eje preservador del patrimonio y su identidad. Y, por último, atendiendo a la preservación, destaca el proyecto portugués "SOS Azulejo" que incide sobre la concienciación del cuidado del patrimonio aboliendo el vandalismo patrimonial, en este caso del azulejado portugués. "SOS Azulejo" se configura como proyecto educativo en 2007, generado desde el Museu da Polícia Judiciária (Loures, Portugal), como medida ante el alto número de robos, vandalismo y abandono que se estaba ejerciendo en este elemento tan característico del patrimonio cultural del país. Entre las varias iniciativas que desarrollan destaca el proyecto con las escuelas "Escuela de Acción Sos Azulejo", desarrollado anualmente con la participación de escuelas del 
territorio nacional, a través de actividades lúdicas que fomentan el conocimiento del azulejo y su fabricación.

En esta misma línea de colaboración entre instituciones, se sustenta la experiencia educativa "Ponte nas Ondas!" (http://pontenasondas.org/es), un proyecto transfronterizo que se desarrolla desde 1995 implicando a diversos centros educativos de Galicia y el norte de Portugal con los niveles de primaria y secundaria, que promueve el intercambio entre jóvenes gallegos y portugueses, a través de encuentros lúdicos y no competitivos para obtener una toma de contacto con la cultura tradicional a través de los juegos populares con fines de sensibilización y lo que su secuencia procedimental implica (Fontal 2003).

muestra recogida en este apartado muestra la relevancia de la implicación ciudadana para con las propuestas patrimoniales de su entorno más cercano. De ellas se destaca que la importancia reside en las personas y no en los propios bienes patrimoniales. Las personas, grupos y comunidades son actores activos que se encuentran en un continuum sobre la construcción de la historia. Así mismo, las personas son las contenedoras de las experiencias, las narrativas de vida, a modo de tesoros vivos de la cultura, de testigos de la misma, poseen conocimientos y experiencias que deben ser preservados, para su conocimiento y transferencia futura.

26 Cuando comunicamos vamos anudando nuestras memorias, compartiendo nuestros saberes y prácticas, elaborando una trama de significados impregnados de nuestra subjetividad como individuos (Guimarães y Goudart 2014). Sin personas no hay patrimonio, en tanto que no se garantiza la viabilidad del patrimonio comprendiendo los procesos de identificación, documentación, investigación, preservación, protección, promoción, valorización, transmisión y revitalización como establece UNESCO (2003). Sin ellas, no existe ni el testimonio ni la mediación para despertar los valores enunciados, ni tampoco el diseño de propuestas que recojan este patrimonio o incidan en la educación patrimonial y el despertar de sus valores. Son las personas las que sienten, diseñan e investigan, en definitiva, las que crean y moldean.

\section{Proyectos artísticos patrimoniales}

La disciplina antropológica se ocupa del estudio de las manifestaciones sociales y culturales de las comunidades humanas y de los rasgos que las caracterizan (Lisón 2007). Desde el origen de la historia, las manifestaciones artísticas han estado presentes como representación del mundo y de su propia creencia espiritual. Cada persona es un ser individual que debe identificarse en el mundo desde la primera expresión gráfica, sin embargo, hay personas que lo hacen de forma creativa a lo largo de toda la vida, pues este proceso de encuentro y de reafirmación como individuo se encuentra latente. Son varios los artistas que trabajan a través de la idea de patrimonio como una forma de expresión, en ocasiones desarrollando proyectos colaborativos que cuentan historias a través de los objetos y las narrativas.

Especialmente significativo ha sido el descubrimiento de los proyectos colaborativos elaborados por la artista y educadora brasileña Izabel Goudart, quien desarrolla sus propuestas en el campo de la educación artística articulando arte, ciencia y tecnologías contemporáneas y tradicionales, trabajando, pues, desde la transdisciplinariedad. A través del diálogo nos hace partícipes de la siguiente reflexión: «los afectos son el 
ingrediente esencial para la creación de vínculos y la transformación de lo cotidiano en el rescate de la memoria y la conservación del patrimonio» (Goudart en prensa). Sus proyectos se desarrollan en contextos artísticos del ámbito no formal y escuelas públicas del ámbito formal.

El primer proyecto "Autonomias do Silêncio" se desarrolló en el espacio rural de arte y tecnología Nuvem, este proyecto fue seleccionado a través de un concurso propuesto por el propio espacio artístico. "Autonomias do Silêncio" aborda el silencio como un recurso natural y patrimonio ambiental en extinción que debe ser preservado. El silencio es un patrimonio inmaterial de la humanidad.

La experiencia de reflexión sobre el silencio dio lugar a la producción de textos y archivos digitales (http://nuvem.tk/sites/silencio/) desde la experimentación de la escucha, la propuesta se asentó sobre los procesos de co-creación, la inmersión sobre el concepto de afecto y la convivencia. Trata de poner en valor el silencio a través de la tradición oral, la cultura del silencio perdida en el tiempo, la contemplación, el disfrute y escucha de la naturaleza in situ, la reverberación que esta hace en la mente humana, la autonomía que proporciona, la transformación del paisaje y, con una connotación poética, la morada de las palabras.

El segundo proyecto "Objetos de Afeto", se desarrolló en colaboración con dos escuelas a modo de proyecto de arte colaborativo, que trabajaba sobre la idea de redes y afectos en el entorno escolar, reflexionando acerca de su importancia en la educación y en la cotidianeidad. Se establecieron laboratorios abiertos donde artistas invitados, diseñadores y educadores elaboraron un libro bordado. Tejieron redes con la comunidad escolar durante más de tres meses donde se recogieron elementos como las redes wifi, presentes en el día a día de los estudiantes, los elementos mobiliarios necesarios para el centro educativo o algunas narrativas de los participantes, tanto individuales como colectivas. Este proceso dio lugar al establecimiento de vínculos y a la reavivación de la vida y los afectos, un trabajo de valorización más allá de los límites curriculares

En estrecha concordancia con este proyecto, trabaja la artista española Rossana Zaera, quien ha desarrollado proyectos como "Cajas de Memoria", donde se propone una instalación basada en la idea de cajas de zapatos llenas de microrrelatos, fruto de las reminiscencias de su infancia, donde entonces representaba su mundo y hoy representa la memoria de aquellos días, como si hubiese quedado atrapada en esas cajas.

El taller "laberintos interiores" es una propuesta paralela que se construye a partir de las historias personales de los participantes que la conforman. Zaera describe:

[...] si yo no contara mi historia y mostrara sus procesos, nadie regalaría a los demás las historias tan personales que se cuentan y comparten en los talleres. Mientras he ido relatando mis propias historias y procesos, las personas han ido conectando con una historia de su propia biografía que es compartida con los demás. Son momentos muy hermosos. Es entonces cuando comienza a emerger el grupo. (Zaera 2015, 252)

Zaera (2015) incide en la importancia del tránsito que se produce de lo escrito a lo representado y la dificultad de trazar las líneas de su relato. Un proceso reflexivo que trabaja sobre la memoria, las historias de vida y el patrimonio personal desde un enfoque creativo y vinculante.

Por último, destacamos el proyecto historia de los zapatos desarrollado en el Centro de día de la Asociación de Daño Cerebral Sobrevenido de Castellón, ATEN3U que basa su práctica en trabajar la identidad y la memoria, a través de un par de zapatos de los usuarios que tuviese importancia para ellos, ya que serían envejecidos desarrollando una 
práctica artística y posteriormente contarían su historia a modo de museo patrimonial respondiendo a la pregunta: ¿Dónde te han llevado estos zapatos?

Con el fin de triangular las prácticas, destacamos a la artista portuguesa Joana Vasconcelos que trabaja con los objetos, los derechos humanos, los papeles de la sociedad y hasta el patrimonio más próximo, como la obra Redes e Rendas. Desde la propia técnica con la que crea sus obras se significa con sus raíces, trabajando con objetos confeccionados al modo de tejer la artesanía portuguesa.

Este segundo bloque de experiencias responde al patrimonio como creación basada en las experiencias de vida de sus autores desde una perspectiva innovadora que implica afectos y procesos sensoriales. Partiendo de sus creencias e imágenes, diseñan acciones que logran conectar a las personas con su patrimonio a través de procesos creativos.

\section{Memoria en red, proyectos singulares}

El patrimonio - visto desde todas sus perspectivas - nos brinda un mar de posibilidades, nos permite abrir nuevas puertas que hasta hace bien poco estaban cerradas, incluso desconocíamos su existencia. Vivimos inmersos en la sociedad digital y de consumo cambiante y volátil -, por ello, el patrimonio adquiere ahora nuevos significados que vienen a añadirse a los que ya estaban.

Hablamos de una enseñanza del patrimonio que reside en la sensibilización de las personas, en el respeto hacia la diversidad, en la preservación de la identidad, la abolición de las fronteras intercontinentales, en el descubrir de la cultura como configurador de contextos, herencia de antepasados, memoria de ancestros, resultado del tiempo y su evolución.

En este sentido, exponemos el caso del Museu da Pessoa (Brasil), un espacio en red basado en el acervo digital, donde las historias de vida y su carga patrimonial son su materia prima. Situado físicamente en la ciudad brasileña de São Paulo, el Museu da Pessoa se erige como un museo virtual, abierto, colaborativo y accesible; un museo que pone en valor la diversidad cultural y la historia de cada persona como patrimonio de la humanidad según nos narran sus educadores. Su meta es contribuir a la construcción de una cultura de paz.

41 A través de las historias de vida de las numerosas y diversas personas que se acercan al museo, este espacio pone en valor su identidad individual y colectiva, reconstruyendo su transcurrir vital y el del pueblo al que pertenece, evitando que este caiga en el olvido y permitiéndole poseer unas bases identitarias.

La institución adaptada a la nueva era tecnológica es un gran "contenedor" de archivos en audio, vídeo, texto, fotos y documentos digitalizados, cuyo común denominador son las narrativas de vida de las personas que se articulan en torno a las siguientes líneas temáticas propuestas por el museo: ciclo de la vida, familia, infancia, amor, pérdidas y superación, medio ambiente, mujeres, internautas, desarrollo industrial, inmigración y migración y profesores.

43 No obstante, puntualmente desarrollan proyectos específicos como "Memoria Local en la Escuela", un programa colaborativo entre el Museu da Pessoa y el Instituto Avisa Lá, donde los maestros aprenden a organizar su práctica para trabajar proyectos sobre la 
memoria y los estudiantes aprenden a escuchar, grabar y difundir historias de vida de los habitantes de sus ciudades a través de la elaboración de textos y dibujos. Esta colaboración ve sus frutos en un libro hecho a mano y una colección virtual en la web del Museu da Pessoa. Para conocer el alcance de la propuesta señalar que entre 2002 y 2013, esta línea de actuación movilizó a 4500 profesores, 45000 estudiantes y 1300 escuelas en varios municipios del país.

En consonancia con este proyecto, se presenta una de las propuestas elaboradas por el OEPE entre las acciones que desde él se desarrollan para la transferencia del conocimiento, la web: https://personasypatrimonios.com/. Esta acción, enmarcada en el ámbito informal, se trata de un proyecto colectivo en el que se comparten los vínculos que las personas establecen con sus bienes, desde el sentido más personal e íntimo. A través de este espacio web, las personas pueden compartir una imagen en la que aparezca un bien patrimonial y acompañarla de un relato que le dote de sentido (real o imaginario). Un locus patrimonial que permite el diálogo y el intercambio con los demás usuarios a través de otros textos e imágenes, con el fin de crear cadenas de vínculos compartidos.

Ambos ejemplos subrayan las historias de vida como fuentes primarias de carácter oral, narrativas que elaboran respecto a sus experiencias o los testimonios escritos que expresan vínculos identitarios sobre algún elemento de su patrimonio personal, suponiendo una forma de preservación de la historia y del conocimiento futuro; poniendo en valor el patrimonio personal y activando la cadena de sensibilización de las personas que visualizan dichos espacios, e incluso, pueden despertar el interés de participar, y acrecentar así la memoria colectiva como si de una cadena de engranajes se tratase.

Estas dos acciones han sido seleccionadas además de, por su alta puntuación en el grado de calidad del diseño educativo a partir de la aplicación del método OEPE (Fontal 2016), por su trascendencia en la actual sociedad digital y de la comunicación, donde las plataformas 2.0 y 3.0 están creando nuevos espacios dialógicos, horizontales, bidireccionales y democráticos, posibilitando así la co-construcción del conocimiento.

\section{Conclusiones}

Nos encontramos ante la necesidad de activar los procesos de identización desde los distintos ámbitos, para lograr una sociedad sustentable y democrática con proyección futura, lo que no se conoce no se desea y de este modo no será efectiva la transformación de la sociedad.

Tras la aproximación al campo desde los diferentes contextos y territorios peninsular e iberoamericano, extraemos algunas pequeñas claves que arroja el conocimiento de los programas más interesantes y efectivos estudiados.

Las propuestas aquí presentes señalan una mayor adecuación a los estándares de calidad tras su análisis. Sus líneas de actuación inciden sobre la práctica basada en los procesos relacionales. Se abordan los proyectos a través de procesos reflexivos, identitarios, de patrimonialización, procesos discursivos, de debate, vinculantes, creativos y críticos. Una metodología activa y participativa que estimula el intelecto y permite iniciar los procesos de construcción identitaria partiendo de las experiencias y los intereses de las personas. 
50 Además, se ahonda en la memoria, los afectos, las emociones, las reverberaciones o los sentimientos. Se trata de fortalecer los lazos de propiedad y pertenencia construyendo nuevas estructuras patrimoniales.

51 Señalar que desde nuestra línea de investigación, se efectúa un análisis y evaluación externa de las prácticas existentes en base al grado de adecuación al diseño didáctico y en base a lo que consideramos las metodologías más efectivas para el logro de los objetivos de valoración, sensibilización y socialización del patrimonio. Sin embargo, son las propias instituciones y/o autores que desarrollan las propuestas, los que deben implementar en su proceso educativo una evaluación interna para conocer los efectos de las acciones y promover la mejora de sus prácticas en aquellos aspectos susceptibles de transformación.

Una vez observados y analizados los tres contextos en su calidad educativo-patrimonial, el estudio nos lleva a considerar que, para establecer estas relaciones identitarias sobre las que teorizamos y desarrollar un óptimo diseño de las propuestas, es necesario tener en cuenta las relaciones del país con su historia, entendiendo cómo son los colectivos y las personas en particular. Cómo son sus relaciones con la ciudad, cómo de fuertes o marcadas son sus tradiciones, considerando incluso el nivel de apego y de valorización de la herencia que poseen y la transformación de su espacio o su contexto social.

Para hacer efectivas las ideas expuestas es necesaria una implicación por parte de los diferentes agentes inmersos en los ámbitos formal, no formal e informal, siendo vital una perspectiva integral, holística y transdisciplinar, para caminar en una misma dirección, que nos lleve al trabajo en grupos multidisciplinares y dentro de las diferentes áreas compartiendo fines y objetivos patrimoniales.

\section{BIBLIOGRAFÍA}

Berger, John. 2002. La Forma de un Bolsillo. México: Ediciones Era.

Blumer, Herbert. 1969. Symbolic Interaccionism: Perspective and Method. Englewood Cliffs: PrenticeHall.

Calbó, Muntsa, Roser Juanola, y Joan Vallès. 2011. Visiones Interdisciplinarias en Educación y Patrimonio: Artes, Culturas, Ambiente. Gerona: Documenta Universitaria.

Calvo, Beatriz. 2015. "Ventanas a Tetuán: Mejora del Paisaje Urbano a través de la Memoria Colectiva." En Educación y Patrimonio: Visiones Caleidoscópicas, coords. Olaia Fontal, Silvia García, y Alex Ibáñez, 151-160. Gijón: Trea.

Cantón, Valentina. 2009. “La Educación Patrimonial como Formación para la Educación

Ciudadana." Correo del Maestro, 154. Consultado en Marzo 12, 2017. http://

www.correodelmaestro.com/anteriores/2009/marzo/incert154.htm

Capel, Horacio. 2014. El Patrimonio: La Construcción del Pasado y del Futuro. Barcelona: Ediciones del Serbal.

Cerillos, María L. 1998. “Apropiación Social del Patrimonio.” Consultado en Marzo 3, 2017. http:// convenioandresbello.org/somos_patrimonio/historia/ 
Criado, Felipe. 2001. "La Memoria y su Huella: Sobre Arqueología, Patrimonio e Identidad." Claves de Razón Práctica 115: 36-43.

Desvallées, André, y François Mairesse. 2010. Key Concepts of Museology. Paris: Armand Colin y ICOM.

Fontal, Olaia, coord. 2013. La Educación Patrimonial: del Patrimonio a las Personas. Gijón: Trea.

Fontal, Olaia, y Alex Ibáñez. 2017. “La Investigación en Educación Patrimonial. Evolución y Estado Actual a Través del Análisis de Indicadores de Alto Impacto.” Revista de Educación 375: 184-214.

Fontal, Olaia, y Carmen Gómez-Redondo. 2016. "Heritage Education and Heritagization Processes: SHEO Methodology for Educational Programs Evaluation." Interchange 47 (1): 65-90.

Fontal, Olaia, y Roser Juanola. 2015. "La Educación Patrimonial: Una Disciplina Útil y Rentable en el Ámbito de la Gestión del Patrimonio Cultural.” Cadmo. International Journal of Educational Researach 23 (1): 9-25.

Fontal, Olaia. 2003. La Educación Patrimonial: Teoría y Práctica en el Aula, el Museo e Internet. Gijón: Trea.

Fontal, Olaia. 2016. "The Spanish Heritage Education Observatory/El Observatorio de Educación Patrimonial en España.” Culture and Education 28 (1): 254-266.

Fontes, Sofía, Carmen García-Gallego, Laura Quintanilla, Raquel Rodríguez Fernández, Pilar Rubio, y Encarnación Sarriá. 2010. Fundamentos de Investigación en Psicología. Madrid: Universidad Nacional de Educación a Distancia.

Fracasso, Liliana. 2016. “Lo "patrimoniable”: Utopías Concretas, Prácticas Artísticas y Hábitat Popular”. XIV Coloquio Internacional de Geocrítica Las Utopías y la Construcción de la Sociedad del Futuro Barcelona. Consultado en Marzo 3, 2017. http://www.ub.edu/geocrit/xiv_lilianafracas.pdf

Gómez-Redondo, Carmen. 2012. "Patrimonio e Identidad: La educación Patrimonial como Vínculo entre Individuo y Entorno." En Comunicaciones del I Congreso Internacional de Educación Patrimonial. Mirando a Europa. Madrid del 15 al 18 de Octubre 2012. Ministerio de Educación, Cultura y Deporte - Observatorio de Educación Patrimonial de España.

Gómez-Redondo, Carmen. 2014. "El Origen de los Procesos de Patrimonialización: La Efectividad como Punto de Partida.” Educación Artística: Revista de Investigación (EARI) 5: 66-80.

Goudar, Izabel. (en prensa). “Objetos de Afeto: Tecendo Redes Colaborativas.” In Patrimônios Possíveis. Goiânia: Universidade Federal de Goiás/MediaLab.

Guimarães, Mariana, y Izabel Goudart. 2014. “Presença, Vínculos e Redes: Por uma Pedagogia da Conectividade." En A Onipresença dos Jovens nas Redes Digitais. Sociotramas, orgs. Cleomar Rocha, y Lucia Santaella, 169-190, Goiás: Cegraf Universidade Federal Goiás.

Juanola, Roser, y Muntsa Calbó. 2007. “La Educación Estético-artística y el Museo. Un Link por sus Recorridos Comunes.” En Espacios Estimulantes: Museos y Educación Artística, eds. Ricard Huerta, y Romà de la Calle, 25-44. Valencia: Universidad de Valencia.

Lisón, Carmelo. 2007. Introducción a la Antropología Social y Cultural. Teoría, Método y Práctica. Madrid: Akal.

Martín Cáceres, Myriam. 2012. "La Educación y la Comunicación Patrimonial. Una Mirada desde el Museo de Huelva." Tesis doctoral, Universidad de Huelva.

Martínez Carazo, Cristina. 2006. "El Método de Estudio de Caso: Estrategia Metodológica de la Investigación Científica.” Pensamiento y Gestión 20: 165-193. 
Martínez Contreras, Javier. 2004. Las Huellas de lo Oscuro: Estética y Filosofía en Ernst Bloch. Editorial San Esteban.

Martínez Rodríguez, Marta, y Olaia Fontal. 2016. "El Binomio Educación y Patrimonio Cultural Inmaterial: Evaluación de Programas Educativos." En Libro de Actas VII Simposio de Didáctica de las Ciencias Sociales en el ámbito Iberoamericano, 624-637. Santiago de Compostela.

MEC, y Gobierno de Córdoba. 2010. "Patrimonio Cultural en Educación." Consultado en Febrero 28, 2017. http://www.bnm.me.gov.ar/giga1/documentos/EL003415.pdf

Mora, Francisco. 2013. Neuroeducación. Madrid: Alianza.

Mouffe, Chantal. 2007. Prácticas Artísticas y Democracia Agonística. Barcelona: Museu d'Art Contemporani de Barcelona.

Pedreira, Gilberto, Juan Ramón Sanz, Hortensia Barderas, Fernando Millán, y Lidia Teira. 2015. "Memoria de los Barrios: Una Iniciativa para la Integración del Patrimonio Cultural Conservado por los Ciudadanos y el del Ayuntamiento de Madrid." En Educación y Patrimonio: Visiones Caleidoscópicas, coords. Olaia Fontal, Silvia García, y Alex Ibáñez, 161-172. Gijón: Trea.

Piñuel Raigada, José L. 2002. “Epistemología, Metodología y Técnicas del Análisis de Contenido.” Estudios de Sociolingüística 3 (1): 1- 42.

Popkewitz, Thomas. 1988. "Los Paradigmas en la Ciencia de la Educación: Sus Significados y la Finalidad de la Teoría.” En Paradigma e Ideología en Investigación educativa, 61-88. Madrid: Mondadori.

Sánchez, Ana. 2015. “Memorias de Madrid: Una Ciudad Construía de Recuerdos.” En Educación y Patrimonio: Visiones Caleidoscópicas, coords. Olaia Fontal, Silvia García, y Alex Ibáñez, 173-188. Gijón: Trea.

Simons, Helen. 2011. El Estudio de Caso: Teoría y práctica. Madrid: Ediciones Morata.

Stake, Robert E. 2005. Investigación con Estudio de Casos. Madrid: Morata.

Stake, Robert E. 2006. Evaluación Comprensiva y Evaluación Basada en Estándares. Barcelona: Ariel.

UNESCO. 2003. Convención para la Salvaguarda del Patrimonio Cultural Inmaterial. Paris: UNESCO.

Zaera, Rossana. 2015. “Paso a Paso: Abriendo Cajas de Memoria." En Educación y Patrimonio: Visiones Caleidoscópicas, coords. Olaia Fontal, Silvia García, y Alex Ibáñez, 249-260. Gijón: Trea.

\section{RESÚMENES}

El presente artículo hace un recorrido por las acciones y programas educativos sobre patrimonio personal, objetos, herencias inmateriales, vínculos y afectos, que se desarrollan en el triángulo investigador establecido en los contextos formativos y culturales de España, Portugal y Brasil. Se desarrolla un estudio a partir del método OEPE (Observatorio de Educación Patrimonial en España) sobre una muestra de $\mathrm{N}=238$ proyectos en torno al patrimonio, de la que finalmente se extraen nueve ejemplos analizados a través del estudio de caso como enfoque investigativo. De los nueve ejemplos, cuatro programas enfatizan en la implicación social con el patrimonio; tres casos se refieren a proyectos artísticos que parten del patrimonio en sus procesos creativos vinculando las historias de vida; y los dos últimos recogen acciones colaborativas en red que inciden en el patrimonio como relaciones, afectos, memorias y vínculos entre personas y bienes. La relevancia del estudio radica en la aportación de prácticas referentes para la mejora de la acción en el campo de la educación patrimonial. Se aborda un breve recorrido por el marco teórico del campo 
de estudio, para desembocar reflexionando acerca de los procesos metodológicos de análisis y evaluación de las prácticas educativas y culminar en la selección de algunos proyectos singulares que sirven de aporte a la disciplina por su carácter excepcional. De forma conclusiva se recogen las claves para que se hagan efectivos los objetivos que la educación patrimonial se propone como disciplina relacional, vincular e identitaria.

This article presents an overview of educational actions and programs on personal heritage, objects, immaterial heritages, bonds and affections that are developed in the research triangle established in the formative and cultural contexts of Spain, Portugal and Brazil. A study based on the OEPE (The Spanish Heritage Education Observatory) method is developed on a sample of $\mathrm{N}=238$ heritage projects, from which nine examples are finally analysed through the case study as an investigative approach. Of the nine examples, four programs emphasize social involvement with heritage; three cases refer to artistic projects that depart from heritage in their creative processes linking life stories; and the last two include collaborative network actions that affect the heritage as relationships, affections, memories and links between people and goods. The relevance of the study lies in the contribution of relevant practices for the improvement of action in the field of heritage education. It deals with a brief tour of the theoretical framework of the field of study, to end up reflecting on the methodological processes of analysis and evaluation of educational practices and culminate in the selection of some unique projects that serve as a contribution to the discipline for its character exceptional. In a conclusive way, the keys are collected so that the objectives that heritage education proposes as a relational, linking and identity discipline can be realized.

\section{ÍNDICE}

Keywords: heritage education, personal heritage, cultural heritage, intangible cultural heritage, identity

Palabras claves: educación patrimonial, patrimonio personal, identidad, patrimonio cultural, patrimonio cultural inmaterial

\section{AUTORES}

\section{OLAIA FONTAL MERILLAS}

Licenciada en Bellas Artes por la Universidad del País Vasco/Euskal Herriko Unibertsitatea, licenciada en Historia del Arte y doctora en Ciencias de la Educación por la Universidad de Oviedo. Es profesora titular en la Universidad de Valladolid. Actualmente dirige el Observatorio de Educación Patrimonial en España (OEPE), una sucesión de tres proyectos de I+D+i y es cocoordinadora del Plan Nacional de Educación Patrimonial en España.

Departamento de Didáctica de la Expresión Musical, Plástica y Corporal, Facultad de Educación y Trabajo Social de la Universidad de Valladolid, Paseo de Belén, 1, 47011, Valladolid, España, olaia.fontal@uva.es

\section{SILVIA GARCÍA-CEBALLOS}

Licenciada en Bellas Artes y en Historia del Arte por la Universidad de Salamanca, máster interuniversitario en Arteterapia y Educación Artística para la Inclusión Social. Es contrato predoctoral del MINECO en el proyecto I+D+i “Educación Patrimonial en España: Consolidación, Evaluación de Programas e Internacionalización del Observatorio de Educación Patrimonial en 
España (OEPE)" - ref. EDU2012-37212. Miembro investigador de diversos proyectos I+D+i (ref. EDU2015-65716-C2-1-R), (ref. FCT-14-9015). Miembro del grupo de Investigación “Educación Histórica y Patrimonial" (EDUHIPA).

Departamento de Didáctica de la Expresión Musical, Plástica y Corporal, Facultad de Educación y Trabajo Social de la Universidad de Valladolid, Paseo de Belén, 1, 47011, Valladolid, España, silvia.garcia.ceballos@uva.es

\section{BORJA ASO MORÁN}

Licenciado en Historia por la Universidad de Zaragoza (2012). Máster universitario en Formación del Profesorado de ESO y Bachillerato (2013). Actualmente, está realizando el doctorado en Educación Patrimonial (Universidad de Zaragoza); concretamente, basa su investigación en el análisis de la educomunicación web 2.0 del patrimonio artístico contemporáneo español. Departamento de Didáctica de las Lenguas y de las Ciencias Humanas y Sociales, Facultad de Educación de la Universidad de Zaragoza, C/ Pedro Cerbuna 12, 50009 Zaragoza, España, basom@unizar.es

\section{MARTA MARTÍNEZ RODRÍGUEZ}

Diplomada en Educación Musical y graduada en Educación Primaria, ambas por la Universidad de Valladolid. Máster universitario en Investigación en Psicología y Ciencias de la Educación, por la Universidad de León. Es investigadora contratada predoctoral de la Universidad de Valladolid, y miembro del Observatorio de Educación Patrimonial en España (OEPE). Ha colaborado en la realización de informes para el Instituto del Patrimonio Cultural de España y es miembro investigador del proyecto I+D+i (ref. EDU2015-65716-C2-2-R) y del grupo de investigación “Educación Histórica y Patrimonial” (EDUHIPA).

Departamento de Didáctica de la Expresión Musical, Plástica y Corporal, Facultad de Educación y Trabajo Social de la Universidad de Valladolid, Paseo de Belén, 1, 47011, Valladolid, España, marta.martinez.rodriguez@uva.es 